\title{
Evaluation of factors of stress among Nursing Students
}

\author{
Parveen $\mathbf{A}^{*}$ and Inayat $\mathbf{S}$
}

Independent Medical College, Faisalabad, Punjab, Pakistan

*Corresponding author: Ayesha Parveen, Independent Medical College, Faisalabad, Punjab, Pakistan E-mail: Ayeshaparveenfsd@yahoo.com

Received date: May 22, 2017; Accepted date: May 25, 2017; Published date: June 2, 2017

Copyright: ( 2017 Parveen A, et al. This is an open-access article distributed under the terms of the Creative Commons Attribution License, which permits unrestricted use, distribution, and reproduction in any medium, provided the original author and source are credited.

\begin{abstract}
Students face different types of stresses during their study. Stress refers to a dynamic interaction between the individual and the environment. Stress is simply the body's non-specific reaction to any demand made on the body. Stress is a psychological factor that influences the academic performance and welfare of nursing students. Therefore, this study was planned with the objective to identify the major stress factors among nursing students of Allied Hospital, Faisalabad, Punjab, Pakistan. The sample size of 150 female participants was selected through simple random methods. For the purpose descriptive cross sectional study design was used. Results revealed that there are many factors which create stress among nursing students but academic, clinical and environmental factors are the major. The $70 \%, 75 \%$ and $60 \%$ participants were agreed and strongly agreed with academic, clinical and environmental factors, respectively, which causes the stress to nursing students. The results of the findings indicate that students experienced mainly academic and clinical stresses which have positive impact on the students learning. The outcomes of the study will be beneficial in designing an accurate stress management package for nursing students of Allied Hospital, Faisalabad.
\end{abstract}

Keywords: Stress factors; Nursing students; Academics; Clinical; Environmental

\section{Introduction}

Stress refers to a forceful interaction between the individual and the environment. In this interaction and boundaries related to work may be apparent as threatening to exceed the person's resources and skills [1]. Stress is not equal with nervousness or anxiety but also provides the originality, abilities and energies; though it can cause tiredness and sickness, either physical or psychologically. Stress is a psychological factor that influences the academic performance [2]. Although every profession is effected by stress but the health professionals are more at risk to stress especially nursing profession [3].

Stress or anxiety is not only a workplace problem but different stressors can also effect the students, which may be stress related to academic performance, or may be due to difficulty to adapt the environment of a new organization. The students may face stressors like social, environmental, academic, emotional, personal, and family. These stressors might disturb the learning ability and academic "performance of the students [4]. The most often reported stressors were failure and uncertainty related to performance and expectations for clinical practice [5].”

Other cause of stress among the students is observed under the personal category. Low self-confidence in the students is common. Confidence is significant for better individual's professional performance [6].

Negative insight towards nursing profession, disrespectful attitude towards nurses and embarrassing behaviour, lack of self-confidence, thinking mistakes, not able to state self and not able to manage time are combined sources of stress in nursing students also the theoretical training, as a result of the above mentioned problems, students have indicated to rapidity conflicts in their individual, household as well as practical lives [7]. The causes of stress connected to the student" is not wanting to contribute in the courses, study load, the anxiety of not being competent to grow up, low levels of course [8].

Academic concerns are very important for individual progress. A student who is getting higher grades then peer mark ably confident and efficient from those students who are not considerable in their studies. So the diminishing of academic growth may lead to the meet in personal, professional and family lives [9].

The most observed sources of stress were fear of failure, doubt about future, lack of confidence, discomfort, nervousness sadness, depression, tiredness, Lack of confidence negative attitudes, low temper, Fatigue decrees sleep and poor satisfaction about performance. Hopefully detection of sources of stress will bring a positive change in student's performance as well as teacher's attitude towards students which is somehow aggressive and ignoring [10]. Stressors can be usually defined as conditions or actions that have the possible to affect health.

The financial position of the students was one of the most associated factors related to causes of stress, this might be due to the financial crisis that affected the whole world and the rise in cost living. Lack of financial prop-up was one of the factors that contributed to stress among university students [3].

Stress is the emotional and physical strain caused by our response to pressure from the outside world. It is specific response by the body to a stimulus that disturbs normal functioning. Stress is not equal with nervous, anxiety but also provides the means to show creativity, abilities and energies; though it can also cause fatigue and sickness, either physical or psychologically. The most observed sources of stress were fear of failure, uncertainty about future, lack of confidence, discomfort, nervousness sadness, depression, lethargy, lack of confidence negative attitudes, low temper, fatigue decrees sleep and poor satisfaction about performance. Hopefully identification of sources of stress will bring a positive change in student's performance 
as well as teacher's attitude towards students which is somehow hostile and ignoring.

Students of Nursing School of Allied Hospital are observed being stressed during academic and clinical hours. It is observed that the nursing students are suffering many issues that hinder student's capabilities. The most observed sources of stress are fear of failure, uncertainty about future, lack of confidence, unease anxiety, sadness, depression, lethargy, lack of self-confidence negative attitudes, short temper lethargy poor sleep and poor satisfaction about performance indicator defined as marker or pointer which gives signal towards something and gives a direction and awareness about which need to be served. The main purpose of this study is to identify the major factors (academic, clinical, environmental) stress among nursing students to improve the performance of nursing students. This study will also be beneficial for the students to identify their factors of stress, by knowing about the factors students can effectively build their coping with stressors and also a good chance for the students to grasp the teacher's attention towards their leading issues which are the cause of stress for students. Somehow it is opportunity for the teachers to know about the student's problem and to find solution for their better adaptation and facilitate the future learner in a good and easy manner to get maximum output. This study was also beneficial for organization to know about students' factors of stress and setting strategies to improve outcome by managing these factors. By exploration of evolution of the factors of stress this study will help to diminish the factors of stress in the training of future nurses.

\section{Objective}

To identify the factors of stress faced by nursing students of Allied Hospital, Faisalabad.

\section{Methodology}

This quantitative descriptive cross sectional research was conducted on nursing students in Allied Hospital, Faisalabad to identify the factors of stress. Targeted population of the study was the students of the nursing school of Allied Hospital Faisalabad. Sample size for this study was 150 students which were calculated according to Slovin's formula $\mathrm{n}=\mathrm{N} / 1+(\mathrm{N}) \times(\mathrm{E})^{2}$

$$
\begin{aligned}
& \text { If total population is } 300 \\
& \text { If N=Population, } \quad \mathrm{n}=\text { Sample size, } \mathrm{E}=\text { Margin of error } \\
& \mathrm{n}=\mathrm{N} / 1+(\mathrm{N}) \times(\mathrm{E})^{2} \\
& \mathrm{n}=300 / 1+(300) \times(0.05)^{2} \\
& \mathrm{n}=300 / 1+(300) \times(0.0025) \\
& \mathrm{n}=300 / 1+1 \\
& \mathrm{n}=300 / 2 \\
& \mathrm{n}=150
\end{aligned}
$$

The range of student's age was between 16 to 25 years. According to data received from students about 77 (51.3\%) students were of 20-25 years whereas $73(48.7 \%)$ students were below 20 years of age. All the respondents were students of diploma in general nursing which includes, $34(22.7 \%), 46(30.7 \%)$ and $70(46.7 \%)$ from $1^{\text {st }}$ year, $2^{\text {nd }}$ year and $3^{\text {rd }}$ year students, respectively. Further, all the students were unmarried.
The study was done through convenient sampling method Questionnaire divided into four sections: Section A cover the demographic data of the participants. Section B questions related to academic factors of stress. Section C questions consist of clinical factors of stress. Section D questions related to environmental factors of stress.

For the purpose, all students were informed that their participation is voluntary and the study is free of harm. Participant's confidentiality and privacy was assured and letter of permission was obtained from the Head of Department of school of nursing of Allied Hospital to precede this research.

\section{Demographic data analysis and results}

This chapter includes three portions of analysis. First analysis was demographic analysis. It gives us details of four demographic questions. Descriptive analysis was used for five variables. Three were independent variables (academic, clinical, and environmental) and one was dependent variable (nursing students). It tells us about the factors of stress among nursing students in Allied Hospital, Faisalabad.

The collected data was interpreted and analysed on SPSS 16.0 version. Descriptive analysis was done, which includes frequencies, percentages and graphical representation.

\section{Result}

Academic sources of stress: Finding of the study showed that most of the respondents $84.6 \%$ were strongly agreed and agreed that Stress level increases due to getting lower grades then anticipation (Figure 1). Similarly, $70 \%$ of the respondents were strongly agreed and agree to another question of academic factor of stress "Inability to balance study and leisure time is source of stress". The $84 \%$ students agree and strong agree to "lack of expected career advancement, fear of future create stress".
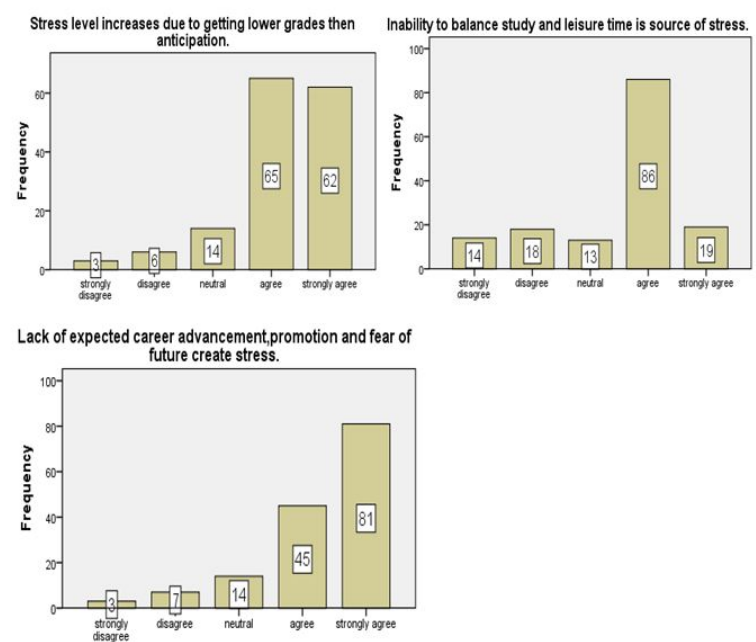

Figure 1: Academic factors of stress.

Clinical factors of stress: Clinical factors of stress is was another factors in which (39.3\%) respondents are strongly agree that maintaining a balance between clinical work and studying increases stress., however, (36.7\%) students were agreed, $8 \%$ are neutral, $(8.7 \%)$ 
Page 3 of 4

are disagreed and $(7.3 \%)$ respondents are strongly disagreed about this question (Figure 2). In response to another question of this contrast in which (44\%) of respondents respond were strongly agree and $45(39 \%)$ were agree which show positive response that humiliating behavior of physicians and being criticizes in front of patient is reason of stress. 17 (11.3\%) of respondents are neutral about this statement, $13(8.7 \%)$ of respondents were disagree and only $9(6 \%)$ were strongly disagree to the statement.
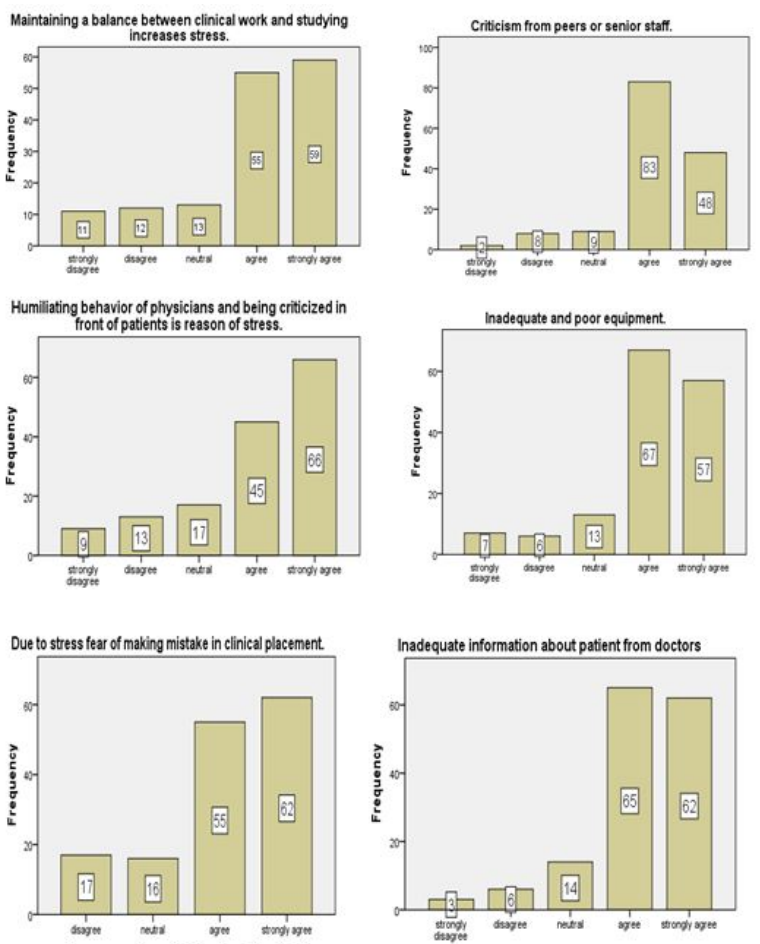

Figure 2: Clinical factors of stress.

The $78 \%$ students were agreed and strong agree stress is due to fear of making mistake in clinical placement. $87.3 \%$ students agree and strong agree that stress increase through criticism from peers and senior staffs. $82.6 \%$ students agree and strong agree that stress is due to inadequate and poor equipment's. $84.6 \%$ students agree and strong agree that stress is due to inadequate information about patients from doctors.
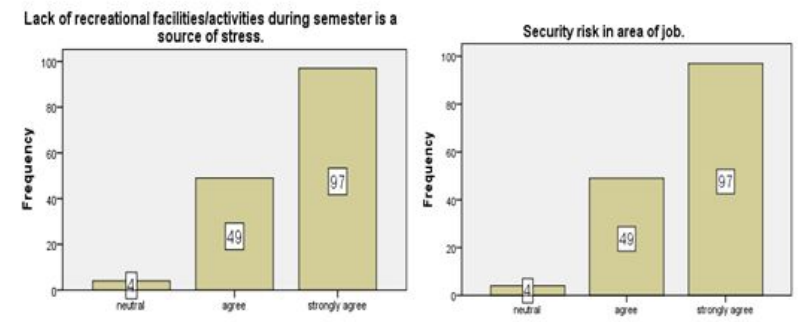

Figure 3: Environmental factors of stress.
Environmental factors of stress: Figure 3 depicted that there are environmental factors which also produced stress among the nursing students. Response to question of this contrast "Lack or recreational facilities during semester is a source or factor of stress". The 97 (64.7\%) of the respondent's response to strongly agree and 49 (32.7\%) were agree to this question which were positive response. $4(2.7 \%)$ of the respondents were neutral about this question. $97.3 \%$ students agree and strong agree that stress is due to security risk in area of job.

\section{Discussion}

Finding of this study indicated that there are a lot of factors among those academic, clinical and environmental factors are the major which caused the stress in nursing students. Finding also showed that most of the respondents $84.6 \%$ were strongly agreed and agreed that stress level increases due to getting lower grades then anticipation. Similarly, $70 \%$ of the respondents were strongly agreed and agreed to another question of academic factor of stress "Inability to balance study and leisure time is source of stress". These results are in line with those of study conducted by Eswi et al. regards stressors among baccalaureate Saudi nursing students in terms of recent life experiences, the academic factors had the maximum contribution in causing stress $(52 \%)$ followed by environmental factors (28\%) while interpersonal factors had the least contribution in causing stress (20\%). For academic stressors (57.0\%) of the students reported a lot of responsibilities as common stressor they are experiencing and considering as very much part of their life; followed by the following academic associated stressors as lower grades hoped for (43.0\%) and too many things required at the same time [11].

Clinical factors of stress were another factors in which (39.3\%) respondents are strongly agreed that maintaining a balance between clinical work and studying increases stress., however, (36.7\%) students were agree, $8 \%$ were neutral, $(8.7 \%)$ were disagreed and $(7.3 \%)$ respondents were strongly disagreed about this question. In response to another question of this contrast in which (44\%) of respondents respond were strongly agree and $45(39 \%)$ were agree which show positive response that humiliating behaviour of physicians and being criticizes in front of patient is reason of stress. 17 (11.3\%) of respondents are neutral about this statement, 13 (8.7\%) of respondents were disagree and only $9(6 \%)$ were strongly disagree to the statement. $78 \%$ students were agree and strong agree stress is due to fear of making mistake in clinical placement. $87.3 \%$ students agree and strong agree that stress increase through criticism from peers and senior staffs. $82.6 \%$ students agree and strong agree that stress is due to inadequate and poor equipment's. $84.6 \%$ students agree and strong agree that stress is due to inadequate information about patients from doctors.

Matrose highlighted in his study about the situations in clinical practice that produced the highest levels of stress were differences between the ideal practice learned in school and real situations in the healthcare environment, indifference from more senior staff and a hostile environment in hospital wards, being criticized in front of staff and patients [12]. One of study conducted by Kirkland examined stressors among 23 female African American baccalaureate nursing students in USA. Data about stressors were collected using a questionnaire and structured interview. The study show that the most frequently reported stressors were failure and uncertainty related to performance and expectations for clinical practice [13]. 
Citation: Parveen A, Inayat S (2017) Evaluation of factors of stress among Nursing Students. Adv Practice Nurs 2: 136. doi:

Environmental factors also produced stress among nursing students and response to question of this contrast "Lack or recreational facilities during semester is a source or factor of stress". 97 (64.7\%) of the respondent's response to strongly agree and $49(32.7 \%)$ were agree to this question which were positive response. $4(2.7 \%)$ of the respondents were neutral about this question. 97.3\% students agree and strong agree that stress is due to security risk in area of job.

Lim et al. also discuss some environmental factor of stress in his study like time pressures, workload, making decisions, continuous changes and economic mistakes at work. According to various reports by occupational health institutions, stress affects almost every profession. However, stressors are high, and there are a greater number of causes of stress among health professionals, especially nurses, with negative consequences for their health [14].

\section{Conclusion}

The outcomes of this study indicates that the nursing students of Allied Hospital, Faisalabad are mainly facing the academic stress which it shows positivity in the students, clinical and environmental stressors have an also great impact on student's learning".

\section{Recommendation}

The findings of this study may be beneficial in designing an accurate management package including organize social skills and fast trainings, stress reducing methods, and counselling techniques to overcome the stress in nursing students of Allied Hospital, Faisalabad. It is also recommended to encourage the faculty and staff to work in cooperation with the students to improve their capabilities."

\section{References}

1. Kohlar (2006) Personal issue such as decline in personal health: J Adv Nurs 66: 442-455.
2. Sawatzky JA (2008) Understanding nursing students' stress: A proposed framework. Nurse Educ Today 18: 108-115.

3. Edwards D, Burned P, Bennett K, Hebden U (2010) A longitudinal study of stress and self-esteem in student nurse. Nurse Educ Today 30: 78-84.

4. Uğur S, Acuner AM, Göktaş B, Senoglu B (2007) Effects of physical environment the stress levels of Hemodialysis nurse in ankara Turkey. J Med Syst 31: 283-287.

5. Pryjmachuk S, Richards DA (2007) Predicating stress in preregistration nursing students. Br J health psychol 12: 125-144.

6. Kutlu Y (2009) Nursing student in clinical practice-developing a modal for clinical supervision. Nurse Educ Pract 2: 4-11.

7. Cohen-Scali V (2003) The influence of family social and work socialization on the construction of the professional identity of young adults. J Career Dev 29: 237-249.

8. Ross SE (2008) Causes of stress among nursing students. J Adv Nurs 66: 442-455.

9. Andrew GJ, David AB, Justin PA, Edith H, Thomas GB, et al. (2006) Professional roles and communications in clinical placements: A qualitative study of nursing students' percipation and some modal for practice. Int J Nurs Stud 43: 861-874.

10. Karaoz S (2002) Nursing stress among nurse education in practice. 6: 10-12.

11. Eswi AS, Radi S, Youssri H (2013) Stress/stresor as percived by baalurate saudi nursing student. Nurs Educ Today 30: 78-84.

12. Martose MP, Landa A, Zafra EL (2012) Sources of stress in nursing student: A systematic review of quantitative studies. Int Nurs Rev 59:15-25.

13. Kirkaland ML (1998) Stressors and coping strategies among successful female African American baccalaureate nursing student. J nurs Educ 37: 5-12.

14. Lim (2010) British Journal of Health Psycology. 12: 125-144. 